\title{
Transcending the Professional-Client Divide: Supporting Young People with Complex Support Needs Through Transitions
}

\author{
Kathy Ellem ${ }^{1}$ (D) $\cdot$ Louisa Smith $^{2}$ (D) $\cdot$ Susan Baidawi ${ }^{3}$ (D) Adrienne McGhee $^{1}$ (D) Leanne Dowse $^{4}$ (D)
}

Published online: 19 January 2020

(c) Springer Science+Business Media, LLC, part of Springer Nature 2020

\begin{abstract}
Young people with complex support needs frequently experience multiple intersecting forms of disadvantage including experiences of violence, abuse and neglect, housing instability and homelessness, problematic substance use, exclusion from education, and contact with the criminal justice system. Many of these young people have mental health, cognitive disability and/or other health issues that also impact on their lives. These young people need to navigate multiple, diverse, and often difficult transitions between services, adding to the existing chaos in their lives. This article explores the experiences of young people with complex support needs in transition, specifically young people's viewpoints and experiences of supports they receive from paid professionals. This qualitative study used body mapping research methods and in-depth interviews with 38 young people aged 16 to 26 years in three Australian states. Helpful and trusting paid relationships could serve as an anchor to young people during complex transitions and other highly turbulent life periods. These relationships were contingent on a deep and non-judgmental knowing of the young person, contributed constructive outcomes and stability in young people's lives, and for some young people, had 'life-saving' effects. These findings present opportunities and challenges for policymakers and practitioners to balance the tensions between authentic relationship-based work with young people and risk-averse, economically-driven imperatives in contemporary youth service provision.
\end{abstract}

Keywords Young people $\cdot$ Complex support needs $\cdot$ Transition $\cdot$ Relationship-based practice $\cdot$ Body mapping

The concept of 'youth transition' has great currency in social science research and in policy and service provision targeted at youth (Storø, 2017; Strnadova \& Cumming, 2016). Transition can broadly be defined as a change in status or role of an individual, which can potentially occur over a multitude of contexts, including moving between or within social structures and across the life course (Harms, 2010; Strnadova \& Cumming, 2016). Normative understandings of youth transition have been contested during the last few decades, with recognition that changes such as the transition to

Kathy Ellem

k.ellem@uq.edu.au

1 School of Nursing Midwifery and Social Work, University of Queensland, St Lucia, Australia

2 Australian Health Services Research Institute, University of Wollongong, Wollongong, Australia

3 Department of Social Work, Faculty of Medicine, Nursing, and Health Sciences, Monash University, Clayton, Australia

4 School of Social Sciences, University of New South Wales, Sydney, Australia adulthood can vary according to cultural and social contexts (Storø, 2017), and are seldom linear or uni-dimensional (te Riele, 2004). Despite these shifts in thinking around transition, much of the research on youth transition is sector or domain-specific, or focuses on singular transitions, such as leaving out-of-home care (Sulimani-Aidan, 2017), the transition to independent living arrangements (Bramsen, Kuiper, Willemse, \& Cardol, 2019), or finding employment (Stafford, Marston, Chamorro-Koc, Beatson, \& Drennan, 2017). Such studies can explore issues within particular contexts or timeframes in-depth, but fail to examine the interconnectedness and overlaps of transitions (Smith \& Dowse, 2019). Adopting a uniform and simplistic framework for understanding change is especially problematic for young people with complex support needs whose experience is likely to transcend service boundaries and singular understandings of transition; and who experience multiple and interlocking disadvantage across the life course (Ellem, Baidawi, Dowse, \& Smith, 2019).

In this paper, complex support needs refers to a combination of co-occurring needs experienced by a young 
person which can include but are not limited to: cognitive and learning disabilities; mental illness and other impairments; physical disabilities; substance misuse; behavioural difficulties; social disadvantage and social isolation (Dowse, Cumming, Strnadova, Lee, \& Trofimovs, 2014). Experiences of transition for young people with complex support needs are frequently far from normative. These young people must often navigate a plethora of multi-faceted transitions which can include experiences of violence (Lamb, Humphreys, \& Hegarty, 2018); rejection and exclusion from formal education and other services (Paget et al., 2018); criminalization at an early age and frequent contact with police (Ellem \& Richards, 2018); the loss of essential resources such as housing and/or income (Couch, 2017; Mott, Keller, Britt-Rankin, \& Ball, 2018); and breakdowns in informal supports such as removal from families of origin, continual relocations resulting in instability and the loss of supportive relationships (Jakobsen \& Christiansen, 2011; Atwool, 2016).

In lieu of supportive family and other informal relationships, young people with complex support needs are often reliant on formal services for care and support (Smyth, 2017). Formal services cut across several sectors including housing, income support, mental health and disability services. The relationships that young people develop with workers within such contexts have the potential to restore young people's sense of worth and competence or exacerbate disadvantage (Sandu, 2019). In some service contexts, such as child protection and youth justice, young people enter service-user/worker relationships as involuntary clients, where the professional has a role in governing the young person's behaviour and life circumstances. These relationships may be actively resisted by young people as a strategy to gain some agency in their situation (Munford \& Sanders, 2017). All of these service systems may contribute to additional instability as young people move from one service to another and one professional relationship to another (Smyth, 2017). Services which aim to assist the young person may fail to provide sustained support, or place conditions on receiving support that a young person cannot meet (Ellem et al., 2019; Smyth, 2017).

Research into at-risk populations, including young people with complex support needs, has demonstrated that relationally oriented service approaches are highly valued by clients (Kirkpatrick, Barlow, Stewart-Brown, \& Davis, 2007; Reimer, 2014). A service can become relationally oriented when primacy is given to the common humanity between service users and professionals, and an egalitarian approach is taken to achieve positive outcomes for clients (Turney, 2012). A helpful client-worker connection enables clients to take control of their circumstances (Ellem, 2019), and results in learning and personal growth (Ellem, O'Connor, Wilson, \& Williams, 2013; Munford \& Sanders, 2017). When a person's ontological need for relationship is addressed, this can be more effective at delivering outcomes than professionalised and distanced therapies and interventions (O'Leary, Tsui, \& Ruch, 2013; Parr, 2016). While there exists a substantial body of research on the value and effectiveness of relationship-based approaches to working with high-risk young people and young people with complex support needs (for example, Almqvist \& Lassinantti, 2017; Mason, 2012), attaining genuine insights from young people themselves about service relationships has been a complex endeavour (Harder, Knorth, \& Kalverboer, 2013). Many of the challenges faced by practitioners in building rapport with young people with complex support needs are also applicable to the research context. This group are likely to have previous experiences of adult professionals betraying their confidences, and may be distrustful of a relative stranger wanting to engage them in research (Vander Laenen, 2009). In addition, researchers may have their own instrumental and strategic motivations for engaging young people in research processes that do not necessarily align with the young person's views (van Bijleveld, Dedding, \& Bunders-Aelen, 2014).

Youth roles in research have varied from more passive participation, such as answering questionnaires designed by researchers (for example, McCloughen, Foster, Marabong, Miu, \& Fethney, 2015) to more active representation, which can move beyond familiar research practices to creative, flexible approaches such as arts-based research methods (for example, Mah, Gladstone, King, Reed, \& Hartman, 2019). This paper reports on research that has taken a middle ground on the co-construction of knowledge regarding relationshipbased practice. The study has elicited the views of young people with complex support needs through a combination of the more traditional qualitative research method of semistructured interviews and the multi-modal, arts-based method of body mapping. By adopting both approaches, this study has facilitated the involvement of a diverse group of young people, with varying levels of discursive abilities, and a wide variety of service and life experiences. The findings are part of a larger Australian Research Council (ARC) Linkage project, "Lost in Transition", aimed at investigating the transition support needs of young people with complex support needs from the young people's standpoint, service provider standpoint, and policy context. Based at the University of New South Wales, the project involved a partnership between academics in NSW, Queensland (University of Queensland), and Victoria (Monash University and Latrobe University), as well as partner organisations in each of the three states.

\section{Method}

\section{Study Design}

This study employed a qualitative multi-method research design using semi-structured in-depth interviews and body 
mapping to explore the lived experiences of transition for young people with complex support needs. The research design had some elements that aligned with participatory action research. It sought participatory engagement and collaborative partnerships with young people in the design and collection of data (Wilson \& Flicker, 2014). The design was informed by an advisory group of young people with complex support needs who recommended that participants be provided with a range of options for participation including: group or one-on-one participation; telling their story in different ways (through body mapping, lifeline mapping, or an interview); having a support person present; and telling their whole life story or focussing on one personally significant transition. By using multiple methods, the researchers were able to explore the lived experiences of transition in both structured ways via in-depth interviews, and in a more flexible and intuitive manner via body mapping. Ethics approval for the study was obtained from the University of New South Wales Human Research Ethics Committee (Approval HC16950), with expedited approval provided by The University of Queensland, Monash University, and La Trobe University.

\section{Recruitment}

Participants were recruited for the study using purposive sampling techniques. Participants in the study met two main criteria for inclusion. The first criterion required that young people participants were aged between 16 and 26 years (for body mapping) or 18 and 25 years (for individual interviews). The age range was adjusted for body mapping in consultation with service providers and partners who felt that the narrower age range would not facilitate access to certain groups of young people located in rural areas or who lived with an intellectual disability. These age ranges aligned with existing policy from multiple service sectors who support young people. The second criterion required that young people's experiences of transition were congruent with the study definition of complex support needs which included experience of two or more of the following: having resided in out-of-home care; living with intellectual or other cognitive disability; experiences of mental illness; homelessness or housing insecurity; specialist or alternative education; problematic drug and alcohol use; and/or police or youth justice contact.

Recruitment of participants occurred through service provider organisations. Organisations from a range of human service sectors were invited to attend forums held in all three states about the research, and a number of these organisations agreed to facilitate contact between young people with complex support needs who accessed their services and the researchers. The service providers acted as important intermediaries, identifying eligible participants, informing them about the research and the various choices that participants had regarding it, answering questions, and, providing written voluntary informed consent forms. In recognition of their contribution to the research, young people participants received a $\$ 50$ pre-paid debit card. Given the sensitive nature of the research and the potential for young people to disclose distressing information, participants were all connected with support services even if informally.

\section{Participants}

The overall participant sample comprised 38 young people, with 31 young people aged between 16 and 26 years participating in body mapping, and seven young people aged 18 to 24 years participating in individual interviews. Recruitment of young people ceased once it was established there was a sufficient diversity in transition experiences, resulting in data saturation. Of the participants who undertook body mapping almost two-thirds $(n=19)$ were from urban centres, a quarter were from regional areas $(n=8)$, and four were from rural areas. All of the interview participants resided in metropolitan locations. Approximately half of body mapping participants $(n=18)$ identified as male, a third $(n=11)$ as female, and two as gender non-binary. Individual interview participants comprised four males and three females. Four body mapping participants identified as coming from culturally and linguistically diverse backgrounds (13\%), and two participants identified as Aboriginal Australians (6\%), with the remainder not acknowledging their background. Participants were either assigned pseudonyms (interview participants) or created their own (body mapping participants) which were used in data analysis and reporting.

\section{Data Collection Methods}

\section{Interviews}

Semi-structured individual interviews were undertaken by a research assistant between December 2017 and March 2018. Individual interviews broadly invited participants to reflect on, and describe their experiences of, past, current and anticipated transitions. Socio-demographic information (age, gender, indigenous status, number of schools, mental health and disability-related diagnoses, out-of-home care and youth justice involvement) was also collected. Interviews were audio-recorded and transcribed verbatim for analysis.

\section{Body Mapping}

Body mapping is an arts-based research method which results in the creation of body maps that visually represent facets of people's lives, bodies and the worlds in which they live (Gastaldo, Rivas-Quarneti, \& Magalhães, 2018). Body 
mapping facilitates non-verbal story-telling and encourages imagination and creativity, allowing participants to reflect on emotions and thoughts using visual, verbal and kinaesthetic modalities (Dew, Smith, \& Collings, 2018; Gastaldo et al., 2018). It is particularly useful in research with individuals with complex support needs who may have difficulty participating fully in verbal-centric research (Dew et al., 2018). The adaptation of body mapping as a research method for this study is explained in depth in Smith and Dowse (2019).

Twenty-one body mapping sessions of between 1 and 4 h' duration were conducted, including three group sessions (totalling 12 participants) and 19 individual sessions. Sessions commenced with a discussion about 'big transitions', with the researcher sharing one or more of their own personal transitions. Participants were then invited to choose the transition they wished to body map, using a range of art and collage materials. During and after construction of the body maps, participants were invited to explain their choice of symbols and what they represented in the transition experience. These explanations enhanced credibility by allowing the researcher to check meanings and interpretations with the young person (Lincoln \& Guba, 1985). Where participant permission was obtained, body mapping sessions were audio-recorded. Researchers also took field notes about participants' stories, and descriptions of researcher/support person-participant interactions.

As body mapping is an active methodology incorporating multi-modal forms of communication, recordings were selectively transcribed to document those sections of the process where young people communicated rich verbal accounts of transition. These accounts were combined with researcher field notes and synthesised into a detailed narrative description of each body mapping session (a testimonia). This narrative approach was based on the ethnographic concept of constructing rich, thick description discussed by Geertz (1973) and included a depiction of the story presented by the body map; an account of the symbols, and their placement and intended meaning in the body map; and a key that explained the symbols. The construction of a holistic account of the body mapping experience for each participant enabled researchers to articulate the multi-faceted complexity of young people's experiences of transition with depth and meaning.

\section{Data Analysis}

Data collection generated two sets of data for analysis. Individual interviews generated verbatim transcripts, and body mapping resulted in both visual body maps and detailed narratives about the body maps and the field notes about the process used to construct them. Analytical approaches to body mapping are underdeveloped and emerging (Orchard, 2017), and data analysis in this study reflects that developmental status. In this study, visual images of body maps were initially analysed using content analysis. A table of symbols used in the body maps was developed to identify patterns across the data. Each symbol was grouped into types related to their location on the map (i.e. whether inside or outside of the body); whether the symbol was text or image; and the overarching meaning of the symbol (for example, the depiction of support persons, or the expression of particular emotions). Content analysis enabled researchers to confirm that key aspects and symbols included in the visual images were considered, and facilitated analysis of the types, uses, meanings and locations of symbols as presented in various sections of the body maps. Narrative body mapping data, the results of the content analysis, and young people's interview transcripts were all analysed using grounded theory methods (Glaser \& Strauss, 1967) as discussed in Charmaz (2014). Initial line-by-line coding of narrative body mapping data, body map content analysis, and interview transcripts was undertaken. The line-by-line coding used the heuristic device of gerunds, allowing the researchers to gain a sense of action from young people's accounts, stay close to the data and begin understanding the content from young people's perspectives. This process was also complemented through the use of memo-writing, which assisted the researchers in determining their analytical direction (Charmaz, 2014). Coding was subsequently organised into higher order categories based upon shared characteristics and themes using the constant comparison approach described in Braun and Clarke (2006). Cross-coding of the interview transcripts by the first three authors of transcripts and body mapping narratives ensured consistency of themes and minimised individual researcher biases (Barbour, 2001). The combination of textual and visual data enabled a rich understanding of young people's lived experiences, including their accounts of paid relationships.

\section{Results}

\section{Young People's Experiences of Transition and Formal Supports}

Most young people with complex support needs in this study shared personal transition experiences that were deeply confrontational, chaotic and traumatic, including experiences of drug-induced psychosis or serious health issues; the intersection of pregnancy, parenthood and homelessness; transitions in and out of prison; and unexpected deaths of key people in their lives.

Many young people reported feelings of low self-worth and diminished agency during transitions, and more than three-quarters of participants had been diagnosed with or sought support for mental health issues. In their body 
maps, several participants reflected experiences of mental illness using potent symbols to illustrate debilitating feelings such as grief and loss. As discussed in previous work (Smith \& Dowse, 2019), young people at times represented themselves drowning under water, floating unheld, and barely existing. Participants' frequent use of the foetal position and drowning appeared to symbolise being 'stuck' or 'trapped' in a liminal space between life and death or different worlds (Smith \& Dowse, 2019).

Other young people portrayed experiences of mental illness as an amorphous entity, easily permeating their natural defences (such as skin), taking over their minds and bodies and, in some cases, hijacking their lives. Winslow, for example, depicted his experience of depression as a 'cloud' of blue wavy lines surrounding his body (Fig. 1), simultaneously an intrinsic state of being, yet external to his experience.

Instability in young people's informal supports often led to early, and sometimes extensive interactions with formal systems. Study participants sought assistance from, on average, four formal service systems during transitions, although given their complex life histories this is likely an underestimate. Service systems mentioned by young people included mental health, education and training, income support, homelessness and housing services, child protection (including out-of-home care and residential care), health, the justice system (including adult justice, youth justice and police contact), disability, alcohol and drug services, employment services, family and/or youth services, multicultural and refugee services. Young people's positive engagement with workers within these systems is discussed in relation to three co-existing domains: affirming the young person's identity, small acts of potent meaning for young people, and personalising the professional-client relationship.

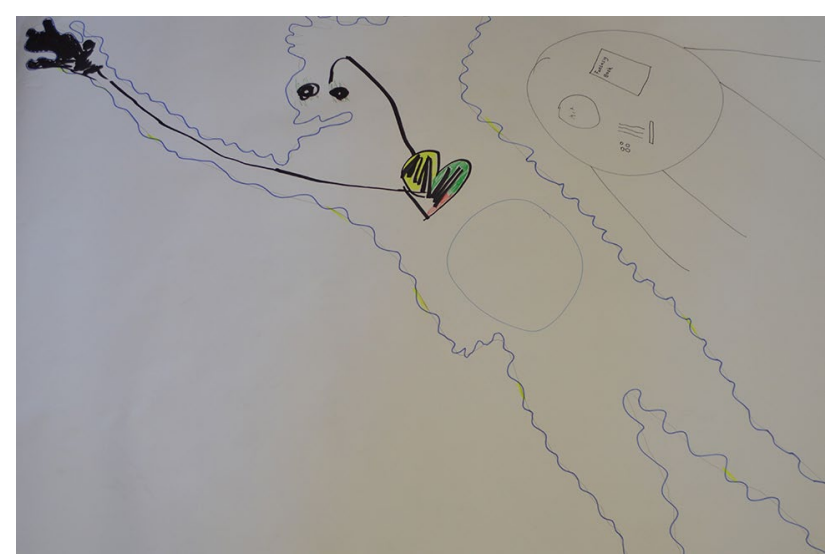

Fig. 1 Segment of Winslow's body map

\section{Positive Experiences of Paid Relationships}

\section{Affirming a Young Person's Identity Through Listening and Respect}

Relationships with paid workers were at times integral to young people's experiences of transition and the identities they constructed during these critical times of change. Daniel, for example, spoke about the many ways in which workers who had entered and exited his life, had shaped his identity and restored in him a sense of trust in relationships-“"Those people have helped craft who I am, my personality, my likes, dislikes, and everything like that. And I know I can count on them if I need anything in the future."

Young people also reported how engagement with workers could sometimes be a potent mitigating factor against the negative outcomes of transitions:

It was either kill myself or get help... I just came here

- I couldn't hold it together...So sick of not having anyone, felt like a bad cold that was never going to end...I wanted to live but I didn't know how to... so I came here and got help...now I'm living. (Eliza)

Young people expressed a need for workers to display genuine interest in connecting with them, and to understand and accept what was important to them. Being noticed, heard and known by adults who could affect the outcomes they needed and desired was fundamental to a positive experience of transition. Young people detailed positive experiences with workers who listened non-judgementally to them. This was an essential feature of workers who were permitted into young people's 'dark spaces', and invited to accompany them through transitions. Robert, who depicted himself as an invincible, magical super hero in his body map (capturing his transition through drug-induced psychosis), saw his social worker as someone he could communicate with deeply. According to Robert, the worker conveyed an ability to listen to him, had "...seen what was going through my mind", and accepted him without judgment:

It would have hurt and destroyed my family to tell them this stuff. I didn't trust the mental health team yet as I was still unwinding my mind after the psychosis but I trusted my social worker because she didn't judge and I felt like she was learning from me about the drug scene; things she didn't know or understand. She was the one person I could talk to about what I was doing or how I felt.

While Robert understood the central importance of nonjudgmental listening by workers, even in areas that may have challenged them professionally or personally, for Mandy, a young person with autism, authentic listening was about hearing what young people valued and needed in their lives, 
and then enacting those preferences. He reflected on his desire for a space of his own while still accessing supports when, and how, he chose. His body map, dotted with random 'foot' markings, highlighted his need to shape the nature of his support- "All the foot marks [made by our dirty feet] mean that you weren't controlled, you weren't programmed, you weren't designed for one purpose. You've got your own free will." In constructing his body map, Mandy explained his initial concerns about his transition to independence, expecting workers:

...to be on my back all the time, telling me to do this and that. At first they were like that and then I just told them, "I'm a loner and I like things my own way." And then they understand that.

Mandy communicated his need for solitude and control to his workers, who responded accordingly, giving Mandy the opportunity to carve out a space of his own. His subsequent transition to independence had a deeply positive impact, improving his relationships with family and creating opportunities to develop an independent identity.

\section{Acts of Potent Meaning in Young People's Lives}

Young people showcased connections with workers whose actions addressed crucial needs and made practical contributions to their lives. Many young people talked about workers who were able to identify pathways through disruption or crisis. Alice was homeless from the time she became pregnant until when she became a mother. She depicted her experience of this time on her body map as drowning (Fig. 2). Alice's body map, shows her submerged in the ocean, anchored to the sea floor by large rocks symbolic of an abusive family member who prevented her living in her previous home. Black seaweed wrapped around her feet represented a depression that dragged her downwards. The practical actions of Alice's housing worker during her transition through pregnancy, homelessness and parenthood, became immensely important to her:

...three months after seeing [the housing worker] they got me a house. So I got our little family back. ... Coming here was basically like feeling like you're drowning and someone pulling you out. ... Someone you don't know wants to help you, that's the best feeling ever

The housing worker's provision of 'life-saving' assistance to Alice during a time of crisis (symbolised in her body map as a rescuer on solid ground throwing Alice a life buoy), also encouraged Alice to explore inner sources of strength"Seeing [the housing worker] has made me realise that I can make those choices. I feel stronger".

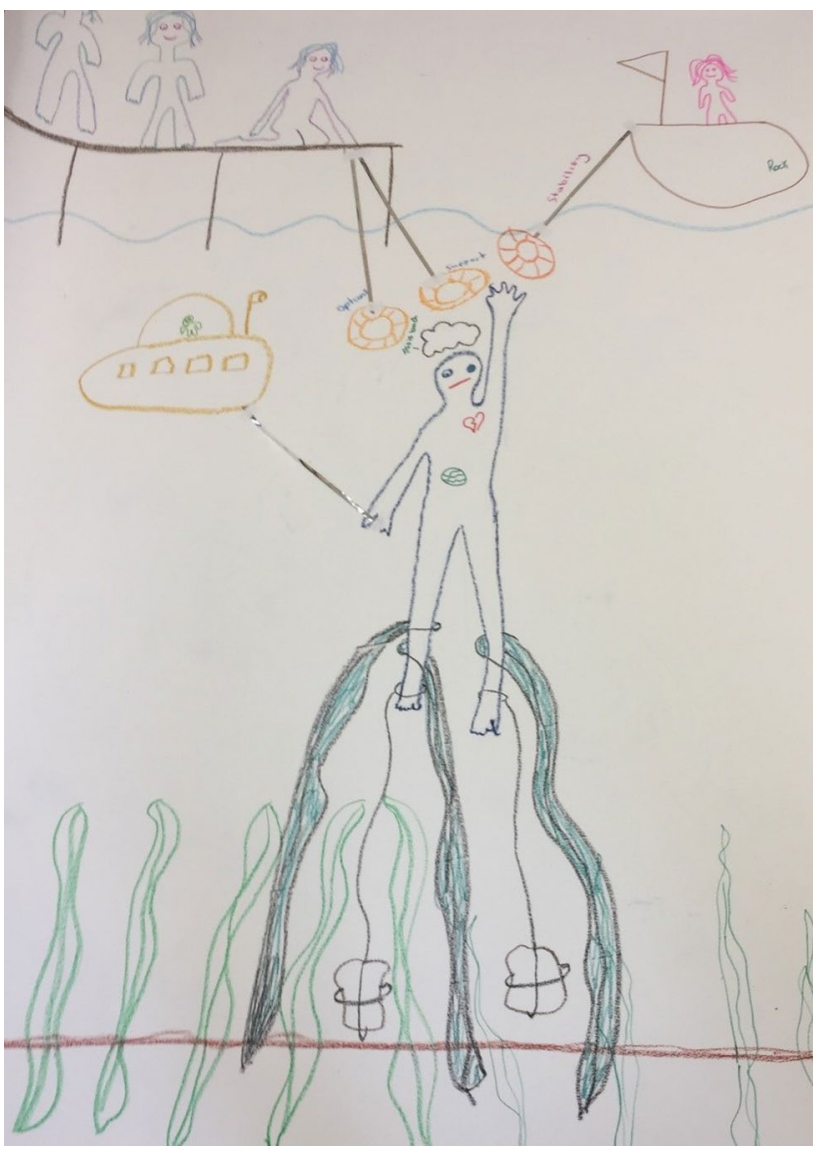

Fig. 2 Alice's body map

Lucy's worker similarly used her knowledge of Lucy to coordinate appropriate supports. She worked to facilitate stability for Lucy, following her transitions through seventeen difficult and sometimes threatening housing arrangements, represented as shapeless blobs on her body map. Lucy's worker supported her to keep her three cats in her new permanent home, displayed on the body map by Lucy (Fig. 3) as a distinct house with a sun behind it, depicting its positive association. Lucy's cats, so integral to her life and experiences of transitions, were brought with her to the body mapping session, and showcased at the centre of her body map surrounded with stars signifying their importance. Referring to herself as "mummy", she treated them as her children, talking affectionately to them, and actively engaging them in constructing her body map by painting their paws and encouraging their pacing across the paper. Through recognising the central importance of Lucy's cats in her life, and ensuring that her 'family' could stay together, Lucy's worker safeguarded one of the most stabilising and valued influences in Lucy's life.

Sometimes workers performed actions that seemed minor to young people, but which later came to powerfully affect their development. Daniel described how he developed a 


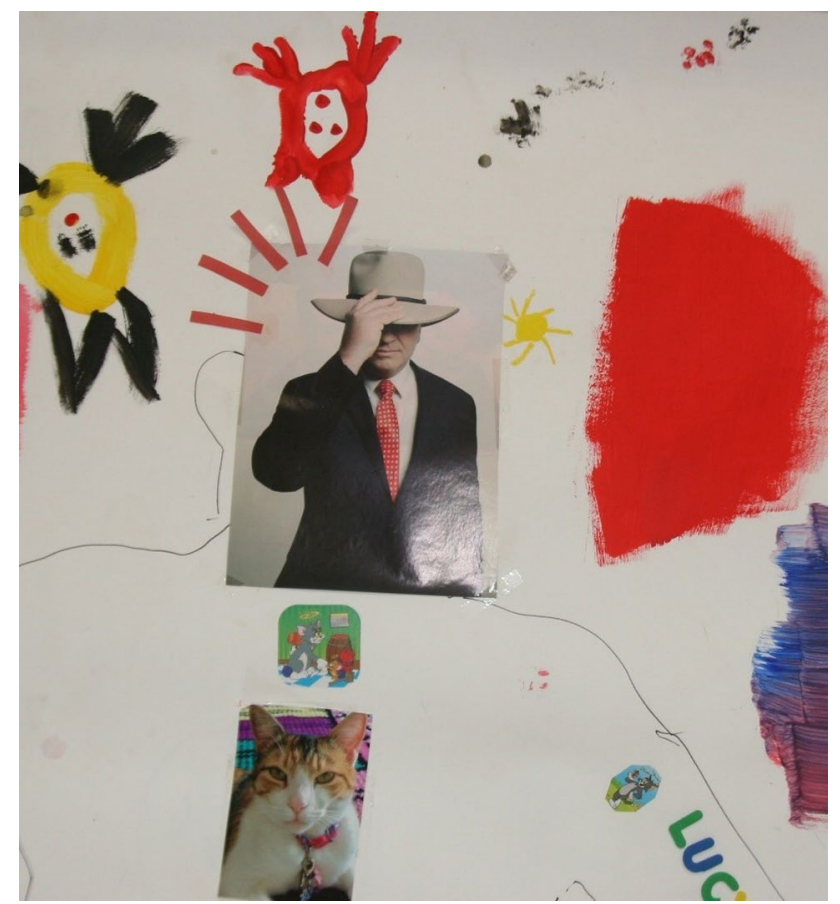

Fig. 3 Segment of Lucy's body map

passion for comics which facilitated his entry into a different world, replete with new connections and experiences, after a worker exposed him to this interest:

A worker once gave me their old - I think it was an $\mathrm{X}$-Men comic or Wolverine comic...That one small act has changed the way I viewed things and lived my life, without consciously thinking of it... And the comics then led into comic movies and this and that, and helped me make friends, and branch out and everything... Like each little thing has affected me in a way that I'd never noticed until purposely looking back on it.

Like Daniel, other young people recalled workers memorably contributing to their development, strengthening their resilience and self-awareness, and preparing them for independent adult living. 6Pac's support worker helped him realise that skill-building was not just about acquiring formal skills or qualifications, but also involved improving self-understanding and emotional regulation. 6Pac showcased this learning on his body map through a thought bubble containing the crossed out word 'anger' outside his body (Fig. 4), representing his capacity to control his anger through anger management and mindfulness strategies learned with his support worker.

Other actions by workers extended beyond supporting personal growth and agency, and involved broader intervention. Several participants talked about teachers providing extensive support and advocacy for them in school

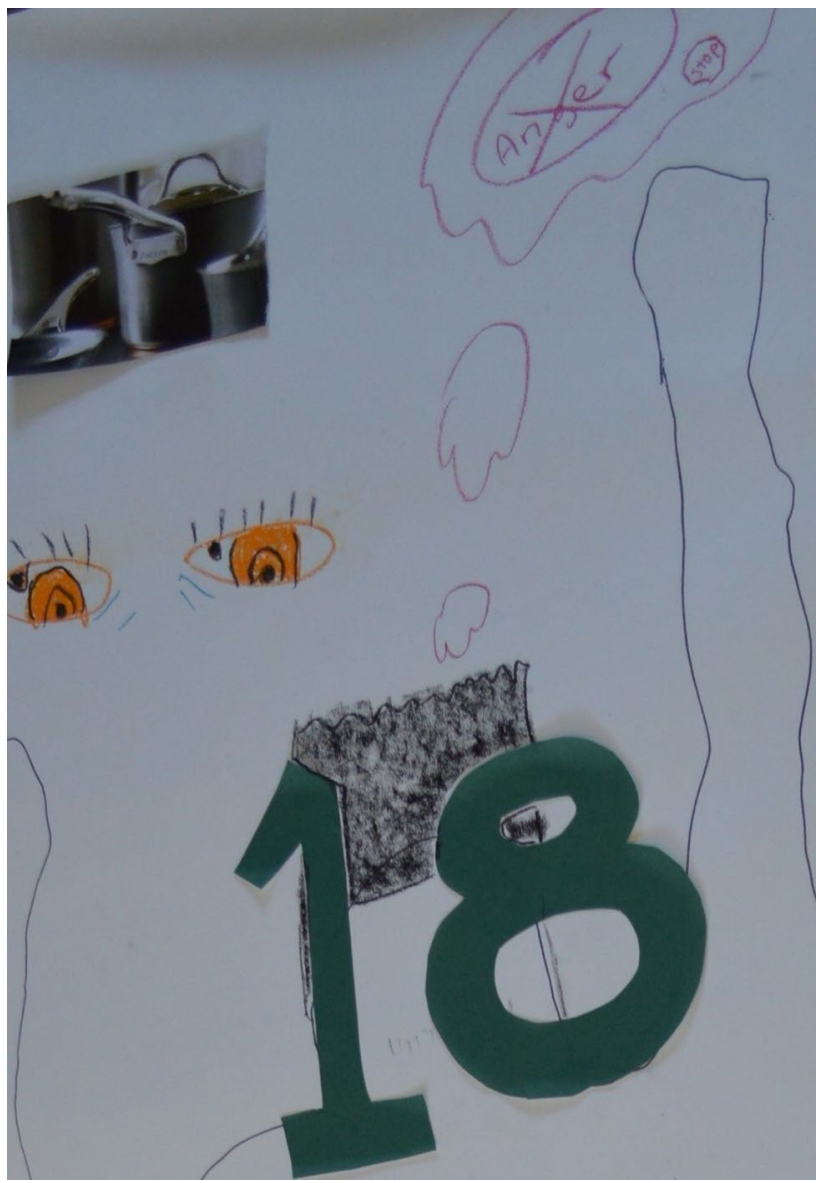

Fig. 4 Segment of 6Pac's body map

environments. For example, Elle Woods, who had to leave her mother's home at age 11 due to the unsafe environment, was bullied all through primary school and during part of high school: "No one did anything" even though she had talked to numerous teachers in the past about the bullying"but he [teacher] actually did something about it...he spoke to him [the bully] and that was good."

Strong young person-worker relationships were scaffolded by practical acts of positive significance for young people, irrespective of their magnitude or frequency. These acts ranged from strategic and systemic interventions, to seemingly small, yet potent, actions that young people described as having a tangible, if not profound, impact on their lives despite other challenges remaining unresolved.

\section{Personalising the Professional-Client Relationship}

While participants consistently identified that workers' actions could substantially impact their lives, young people also described relationships with workers as reinforcing their worth, generating a sense of belonging and being cared for. Such relationships were often viewed as personally 
significant—even life-saving — and workers were frequently referred to as being like 'family' or close friends. Such relationships, which evidenced workers' willingness to exceed the paid functions of their roles, potentially crossing professional boundaries, were seen by young people as genuinely caring, as Grounded explained, "This [current organisation] is probably the most helpful because I feel she actually cares. With [other organisation] all they do is hand me money, they're not doing anything else."

Many young people felt that the caring experienced as a result of family-like bonds with workers had a powerfully motivating influence. The surgeon who undertook Sara's liver surgery was described as motivating her interest in medicine which, at the time of data collection, Sara was pursuing in her tertiary studies. She described how this surgeon's impact on her was accomplished through his looking after her on a holistic level, not only considering her physical health but her emotional stability, and her studies. Sara described him as a father figure who continued to stay in touch with her 5 years later. Sara's body map captured the importance of this relationship, along with the transition experiences, as working out what mattered and finally finding the "bull's eye" in life. Thomas, who described himself as "autistic" and having been "born a feminine mess", talked about not knowing about transsexuals or the meaning of transgender until a disability support worker disclosed that he had been "born a girl", allowed Thomas to touch his facial hair and told him about his transition to a male body. Prior to this time, Thomas wrestled deeply with his gender identity: "I could never explain why I felt so sad about my body." During conversations with the worker, Thomas became overwhelmed with the possibility of becoming transgender- "It was blowing my mind". The worker's sharing of his own experiences helped Thomas make sense of his inner turmoil regarding his own gender identity. This life-changing relationship sparked a gender transition for the young man who previously "could never talk about it [his anger and sadness about his body], it's something I never told no one."

For some young people, relationships with paid workers had life-saving importance. Elle Woods explored the transition of moving out of her mum's home at age 11 to live in a regional city with her 18 -year-old sister. She chose to have her youth worker present whilst making her body map, mentioning this worker as a key factor contributing to her recent happiness:

That's her positive humour. I can be sad but I can't be depressed around you. It's like crazy. We go for hikes and things, like this [is my worker's] role. Sometimes I call her my youth worker, sometimes I call her my friend.

Elle Woods described how she and her worker were active together because she (Elle Woods) felt "more comfortable doing things and talking" than "sitting in a room being asked questions". She described being given helpful advice, understanding, help to improve her state of mind, being heard, and support which made difficult tasks-like talking to police- - "really easy". She added that, without the support of the worker during a difficult period the previous year, "I probably would have ended it there". Elle Woods' body map included a picture of the worker on a skateboard over her heart, surrounded by a love heart to convey the emotionally meaningful nature of the relationship (Fig. 5).

Elle Woods' relationship with her worker mirrored the significant connection that young people might have in close relationships with friends or family: sharing feelings, enjoying each other's company, inspiring growth, and providing support during dark nights of the soul. The deep connection between worker and young person not only acted as a buffer against multiple traumatic and isolating transitions, it enabled the worker to contribute meaningfully in Elle Wood's life on an ongoing basis, successfully supporting her through several confronting and destabilising transitions. Thus for Elle Woods and other participants who developed caring, quasi-familial affiliations with workers, the relationship became a powerful impetus for positive change, in addition to reinforcing participants' sense of being known and valued during difficult life periods.

\section{Negative Experiences of Paid Relationships}

\section{Uncaring Paid Relationships}

In contrast to the relationships with workers described above, participants also reported interactions with workers that were far from what they needed or envisioned. Rather than strengthening young people's self-efficacy and resilience, these interactions and relationships produced no, negligible or negative practical outcomes, such as destabilising living arrangements, being assaulted by police, feelings of abandonment, hopelessness and distrust. For example, Grounded-whose body map depicted her exit from the child protection system and leaving residential care-talked about feeling dejected after being judged by workers at her residential home. Grounded explained how she "...heard a carer talk about me to a young person, saying that like I'm 'backstabbing you' and all this stuff." When invited to show how a non-judgmental worker might be represented on the body map, she was unable to do so. In relaying more of her story, Grounded talked about how workers congregated in an outdoor area of the residential care home to smoke and discuss the young people who lived there, acts which engendered dual effects of feeling criticised and hopeless- "like they're out there smoking and chatting to one another and I feel like I' $m$ being judged. So I'd go back inside and give up again." Similarly, when Alex finally sought help from youth 
Fig. 5 Segment of Elle Woods' body map

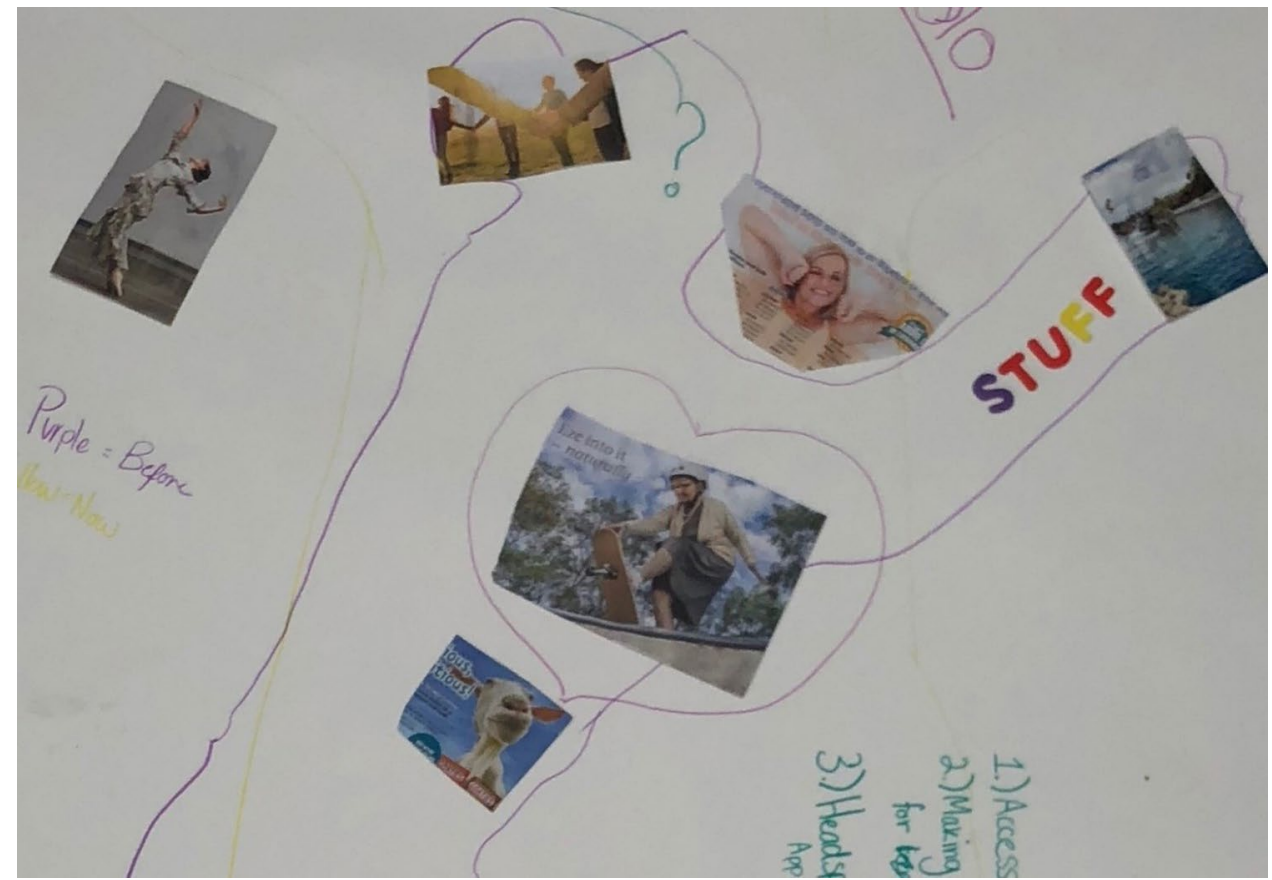

mental health and substance abuse services, he found workers showed little interest in hearing what he and his family knew he needed:

[I was] like "Fuck, I want to kill myself. I can't deal with this," and I called so many different services ... I went with my auntie to [the service]... my auntie said to the guy, "If you let him leave, I'm just scared he's going to do something to himself." And they let me go no worries, no problem. When it comes down to like me saying to them, "I want to be put onto a medication that is like non-addictive for my depression, because I have a problem with you know substance dependence," they did not listen to me.

Other young people talked about remaining unknown and unheard by workers, and consequently being invisible within systems they had expected would support their wellbeing and assist them in their transitions. Daniel described his disengagement from education in order to maintain his property after his housemates' disappearance, observing how no-one at the school noticed his absence until it was too late:

Well, [my housemates] disappeared... I was paying their rent. But I had to drop out of high - I didn't technically drop out at the time; I just stopped going because I had to keep the property in good condition, and blah, blah, because there were inspections and so on and so forth. So I got called into school like a month or two later, after no one had checked on me at all, saying like, 'Oh, you know, you've been away. You've failed."
Several young people communicated instances where workers in formal service systems failed to deliver the practical supports they needed to effectively navigate transitions. Eliza talked about her first social worker who was "alright but so slack...she'd say she'd do something and then never do it". Other young people talked about 'being kept in the dark', describing experiences of workers withholding information, intentionally deceiving them, providing conflicting information, or simply neglecting to tell them what they needed to know to steer their way through complex situations. Young people like Hannah, who had lived in out-of-home care, relayed how information about transitions was often held by others ("everyone knows about it but me"), while she was left confused about the reasons behind the ending of a foster care arrangement:

I felt really bad because I thought that I made her [the foster carer] sick. And then when I left, she got even worse than she had been. And then I felt bad for leaving because I thought that that made her worse, and I was making her better. It was like, I don't know.

In addition to being inadequately informed, participants described being ill-equipped with the knowledge and skills needed to transition into adulthood. Daniel, for example, detailed the anxiety he felt upon realising how poorly prepared he was for independent living - "There's so much I was not prepared for by [name of organisation]: how to properly do your washing, majority of your cooking, budgeting, bills, how to set up bank accounts, all that." 
Other young people considered that some workers were generally less interested in attending to their needs than they were in pursuing their own priorities:

There's a time when I said "I need to go out somewhere, my driving lesson" and she was like "I can't take you now" and I said "what... because you're smoking?" She was literally outside having a cigarette saying "I can't take you right now" with her posh voice, and I said "Look, I've got to go to my driving lesson and I' $m$ sick of being stuck in the house"... Finally after half an hour she finally took me (Grounded)

In some cases, those priorities included subjecting young people to violence as a mechanism for control. James shared his experience of being searched by a police officer:

I had a real nasty police man and he abused me, he assaulted me, he punched me in the face a few times. ... He searched us and stuff, he put me in the back seat, he said "Don't touch that or I'll..." I said, "Is that a threat against me?" He said, "That's it", pulled me out and hit me in the face a few times.

Where workers undermined young people's safety and dignity, and failed to listen, follow through on promises, or engage with them in ways that generated positive outcomes, young people experienced a loss of trust in workers and systems. As Grounded indicated, these types of workers were seen as reflections of uncaring organisations that demonstrated no real interest in, or attention to, young people's wellbeing_ “There's no care. It's called care, but there's no care." These actions similarly reinforced young people's sense of hopelessness and abandonment during transitions, leaving them struggling to meet challenging and traumatic events on their own.

\section{Instability in Young Person-Worker Relationships}

The traumatic and intense nature of many of the transitions experienced by young people with complex support needs, along with the frequent fragmentation and loss of valued relationships during these times, meant that many young people were highly sensitised to instability in their lives. As Jess shared, "I think just stability is just a massive thing with all this happening."

While most young people expressed the importance of having dependable people and stable relationships in their lives, they were aware that their relationships with workers were fragile, and could be dismantled without warning due to factors outside their control. More than half of participants identified that relationships with workers were repeatedly disrupted for various reasons including: changes in the young person's living arrangements, geographical location, and education; suspension, expulsion or exclusion of the young person from school and/or services; changes (including restructures) in services and systems; needing to access and move across multiple systems; the resignation or loss of workers (through, for example, illness); and the loss of eligibility to youth-specific systems and services when young people turned 18 and/or were effectively classified as 'adults'.

Instability in relationships became the norm for young people like Adrian, who had attended six different primary schools and had "always been moving around", and Jess, who described a disjointed 18-month transition in and out of homelessness, temporary mental health facilities, and supported accommodation. Jess attributed her ongoing mental health issues to her perpetual life instability, adding that constant changes in workers and loss of paid relationships meant that she was never able to establish forward momentum through transitions:

Changing workers is kind of like you stop and start again. So, you get somewhere with one worker, and you have to go to another service. And, then if you're on medication, that all changes, because you have to see new doctors, but yeah, just the stop and starting...

Olivia concurred with Jess' "stop and start" effect, describing the momentous effort required to continually readjust to, and abandon, new people and relationships:

Moving's probably the most hardest transition a person could go through... Different family members, or different personalities. Different people, getting to know those people. Different schools, having to get to know teachers and how the teachers are. Schoolwork; especially schoolwork, because that always changes for different schools... It's like a constant building up of relationships and then saying 'bye' to it.

Many young people identified the lack of continuity of workers as among the most dispiriting barriers to having their needs met. Additionally, continual changes in workers and movements across systems left many young people frustrated with having to perpetually share deeply traumatic experiences with new workers. Eliza recalled, "I've had to explain these stories millions of times, every social worker I've met, every person I've ever met I've had to tell these stories to."

A number of young people argued for improving the continuity of workers, including Olivia who said that "more stable relationships with workers" would have contributed to better transition experiences. Jess agreed that "having one person" would have helped with the various transitions she had undergone, providing "something that actually stays the same" throughout her life. This person would act like a key worker "that does like all the session planning and bringing all the workers and carers together." Jess understood 
potential barriers to implementing this approach, observing that "people change, but at least the same service, and the same role", but argued that a single source of contact would provide a stable source of information and planning throughout transitions.

\section{Discussion}

In this study, young people identified experiences of supportive paid relationships in a variety of service systems. These relationships fundamentally involved being known, acting on urgent and practical issues, and supporting their sense of identity, agency, self-worth and connectedness. Unlike relationships where interactions with young people were purely transactional in nature, positively significant acts and relationships brought about successful outcomes for young people and, at best, established foundations for their futures. These outcomes included building skills for independent living; establishing secure housing; supporting their full engagement in education; strengthening their mental health; inspiring vocational choices; testing out new identities and new ways of relating in safe spaces; and finding kindred spirits with whom they could make sense of the chaos involved in transition. As described in other studies of relationship-based practice with young people (for example, Augsberger \& Swenson, 2015; Ungar, Liebenberg, Landry, \& Ikeda, 2012), these relationships involved an emotional connection and offered a vehicle for healing. The findings are also consistent with a relational-cultural theory framework, which proposes that individual resilience can be strengthened through growth-fostering relationships (Hartling, 2009; Jordan, 2014). The young people in this study showed examples of achieving functional and mutually-valued connections with adults, despite having past experiences of fragmented and dangerous relationships.

Acts of potency and caring in paid relationships also prompted the awakening of young people's own capabilities and resilience. Young people consistently highlighted how positive, singular, and sometimes simple and time-limited actions and connections with workers stimulated their own sense of agency and opened the doors to new and positive possibilities. Workers who engaged with young people in these ways did not resolve or seek to resolve every issue the young person brought with them to the service. Worker efficacy was instead based in authentic engagement and the targeting of issues that were of greatest salience to the young person. These findings suggest that much can be gained, even within brief encounters with young people, if workers are attuned to humanistic and flexible ways of relating. This can involve discerning the core concerns of young people which may not always be clearly defined in policy and procedure (Abel \& Wahab, 2017)
Many young people in this study discussed their experiences with individual workers interchangeably with their involvement with agencies and systems. To some extent, these accounts speak about the important part workers play in representing their agency or professional role. Individual positive connections with young people can foster trust and rapport with the service as a whole and provide another point of stability in young people's lives (Malvaso, Delfabbro, Hackett, \& Mills, 2016).

Findings from the study concur with other research on services to young people on the failure of systems to adequately respond to young people's declared need for stability (Augsberger \& Swenson, 2015; Ungar, Liebenberg, \& Ikeda, 2014). Constant disruptions to paid relationships interfered with young people's wellbeing and experiences of transition. While some of the underlying causes of instability in young people's lives lay outside workers' purview (for example, family breakdowns and geographical relocations), young people themselves identified that systemic factors contributing to disruptions in paid relationships could be addressed through changes in service delivery. Participants suggested that effective relationships should 'follow' young people as they navigate various services, proposing access to a single coordinating organisation or worker which/who accesses and negotiates services, provides information, and advocates across systems for the young person until such support is no longer required.

At the service level, this study has considerable implications for how workers and their employing organisations engage with young people with complex support needs, specifically how to optimise the young person-worker relationship while simultaneously managing risks posed by this approach and delivering the outcomes required by funding bodies. Relationship-based practice is often time- and emotion-intensive in nature and may not align with the risk management, cost-effectiveness and efficiency orientation of neo-liberalist service ideology (Broadhurst, Hall, Wastell, White, \& Pithouse, 2010; Oliver \& Charles, 2016). As such, service providers implementing this approach in their work with young people with complex support needs often do so without the resources needed to balance the tension between delivering on-time measurable outputs with properly supporting effective worker-young person relationships.

Given the highly engaged nature of this work, services must often manage additional risks, including the potential for vicarious trauma to workers arising out of close relationship with at-risk young people (Silveira \& Boyer, 2015). The types of paid relationships that are valued by marginalised people (including valuing worker disclosure and considering workers like friends or family) likely generate considerable professional and ethical tensions for workers which must be consciously, carefully and continuously navigated (Shevellar $\&$ Barringham, 2016). A delicate balance is needed between 
interactions that encourage trusting and close relationships with young people, and ensuring that such relationships are purposeful, and account for the time-limited nature of agency involvement (O’Leary et al., 2013). Services can assist individual workers by promoting protective factors against compassion fatigue and burnout, including helping workers to harness social support from personal and professional networks (Hopwood, Schutte, \& Loi, 2019); and enhancing communication and cooperation between team members (Astvik \& Melin, 2013).

\section{Study Limitations}

Young people in this study were recruited through service providers and were, or had been, in receipt of supports and services, some of which were well-established. In contrast, young people with complex support needs who were excluded or self-excluded from services were highly unlikely to be participants of the study, likely generating some sampling bias. Given that important learnings have emerged out of the insights and reflections young people provided about the nature of their supports, along with the potential relevance of these findings for future engagement with excluded members of this cohort, the researchers considered the potential bias to be an acceptable risk of the recruitment strategy.

A second consideration is the potential impact of the presence of a support person in the body mapping interviews. As stated in the methodology, young people were invited to bring a support person to optimise emotional and cultural safety during body mapping, and a number of young people chose their usual worker to support them during this process. Some of these young people shared their feelings about and experiences with these workers during body mapping and were frequently very positive about the support they were receiving from this person. While it is likely that young people chose workers they trusted and valued to participate in the body mapping, and that positive comments offered about workers were reflective of the effectual nature of the relationship, it is also possible that some young people felt compelled to talk more positively about that worker than they might have done in the worker's absence. There were however examples of young people without workers present during data collection but who also shared positive stories about current and former workers. Conversely, some young people who had workers present during body mapping shared both positive and negative stories about workers in their testimonia. The body mapping process allowed young people substantial choice and control over what issues were discussed, and offered an opportunity for young people to express their views on paid relationships in ways they may have never experienced before. Its utility as a research method in eliciting young people's views may also have relevance in the context of professional practice, as a creative way of engaging with hard-to-reach young people.

The use of a qualitative multi-method design allowed for multiple perspectives from young people on their experiences of transition and supports. Participants only used one method, either semi-structured interviews or body mapping. It is possible that if young people were given the opportunity to engage in both interviews and body mapping, there may have been a richer insight into their transition experiences and relationship-based practice. However, both approaches required a significant amount of time and commitment from young people about sensitive issues, and to do both would increase the risk of research participant burden for young people (Lingler, Schmidt, Gentry, Hu, \& Terhorst, 2014). While engagement with individual participants was restricted to one data collection method, the use of both semi-structured interviews and body-mapping across the sample, extended the breadth and scope of participation of young people with complex support needs (Hammond, 2005).

\section{Conclusion}

The views of young people in this study confirm the already substantial evidence base supporting the centrality and importance of paid relationships for young people with complex support needs (Malvaso et al., 2016). The selection of both arts-based and textual modes of data collection enabled young people to discuss and represent aspects of their lives that may often be overlooked in discussions of service provision. In line with the consistent and growing body of evidence in this area along with the movement towards person-centred service delivery across Australian social services, it is well past time to shift relationship-based practice from the fringes of mainstream youth policy and funding and embed relationship at the 'policy heart' of service provision to young people with complex needs.

Acknowledgements This research was supported by the Australian Government through the Australian Research Council's Linkage Projects funding scheme (Project LP150100528). The views expressed herein are those of the authors and are not necessarily those of the Australian Government or Australian Research Council.

Author Contributions Authors KE, LS, SB and LD contributed to the study conception and design. Material preparation, data collection and analysis were performed by KE, LS, SB and AM. The first draft of the manuscript was written by AM and KE and all authors commented on previous versions of the manuscript. All authors read and approved the final manuscript. 


\section{Compliance with Ethical Standards}

Conflict of interest The authors declare that they have no conflict of interest.

Ethics Approval Ethics approval for the study was obtained from the University of New South Wales Human Research Ethics Committee (Approval HC16950), with expedited approval provided by The University of Queensland, Monash University, and La Trobe University.

Informed Consent To participate in the study, participants needed to provide voluntary, informed consent.

\section{References}

Abel, G., \& Wahab, S. (2017). "Build a friendship with them": The discourse of "at-risk" as a barrier to relationship building between young people who trade sex and social workers. Child and Family Social Work, 22, 1391-1398. https://doi.org/10.1111/cfs.12357.

Almqvist, A.-L., \& Lassinantti, K. (2017). Social work practices for young people with complex needs: An integrative review. Child and Adolescent Social Work Journal, 35, 207-219. https://doi. org/10.1007/s10560-017-0522-4.

Astvik, W., \& Melin, M. (2013). Coping with the imbalance between job demands and resources: A study of different coping patterns and implications for health and quality in human service work. Journal of Social Work, 13, 337-360. https://doi. org/10.1177/1468017311434682.

Atwool, N. (2016). Journeys of exclusion: Unpacking the experience of adolescent care leavers in New Zealand. In P. Mendes \& P. Snow (Eds.), Young people transitioning from out-of-home care (pp. 309-328). London: Palgrave Macmillan.

Augsberger, A., \& Swenson, E. (2015). "My worker was there when it really mattered": Foster care youths' perceptions and experiences of their relationships with child welfare workers. Families in Society: The Journal of Contemporary Social Services, 96, 234-240. https://doi.org/10.1606/1044-3894.2015.96.34.

Barbour, R. S. (2001). Checklists for improving rigour in qualitative research: A case of the tail wagging the dog? The British Medical Journal, 322, 1115-1117. https://doi.org/10.1136/ bmj.322.7294.1115.

Bramsen, I., Kuiper, C., Willemse, K., \& Cardol, M. (2019). My path towards living on my own: Voices of youth leaving Dutch secure residential care. Child and Adolescent Social Work Journal, 36, 365-380. https://doi.org/10.1007/s10560-018-0564-2.

Braun, V., \& Clarke, V. (2006). Using thematic analysis in psychology. Qualitative Research in Psychology, 3, 77-101. https://doi. org/10.1191/1478088706qp063oa.

Broadhurst, K., Hall, C., Wastell, D., White, S., \& Pithouse, A. (2010). Risk, instrumentalism and the humane project in social work: Identifying the informal logics of risk management in children's statutory services. British Journal of Social Work, 40, 1046-1064.

Charmaz, K. (2014). Constructing grounded theory (2nd ed.). London: SAGE.

Couch, J. (2017). 'Neither here nor there': Refugee young people and homelessness in Australia. Children and Youth Services Review, 74, 1-7. https://doi.org/10.1016/j.childyouth.2017.01.014.

Dew, A., Smith, L., \& Collings, S. (2018). Complexity embodied: Using body mapping to understand complex support needs. Forum: Qualitative Social Research. https://doi.org/10.17169/ fqs-19.2.2929.

Dowse, L., Cumming, T., Strnadova, I., Lee, J., \& Trofimovs, J. (2014). Young people with complex needs in the criminal justice system. Research and Practice in Intellectual and Developmental Disabilities, 1, 174-185. https://doi.org/10.1080/23297 018.2014.953671.

Ellem, K. (2019). Supporting people with cognitive disabilities in contact with the criminal justice system: The importance of relationship-based practice. Research and Practice in Intellectual and Developmental Disabilities, 6, 164-177. https://doi. org/10.1080/23297018.2019.1629332.

Ellem, K., Baidawi, S., Dowse, L., \& Smith, L. (2019). Services to young people with complex support needs in rural and regional Australia: Beyond a metro-centric response. Children and Youth Services Review, 99, 97-106. https://doi.org/10.1016/j.childyouth .2019.01.033.

Ellem, K., O’Connor, M., Wilson, J., \& Williams, S. (2013). Social work with marginalised people who have a mild or borderline intellectual disability: Practicing gentleness and encouraging hope. Australian Social Work, 66, 56-71.

Ellem, K., \& Richards, K. (2018). Police contact with young people with cognitive disabilities: Perceptions of procedural (in)justice. Youth Justice, 18, 230-247.

Gastaldo, D., Rivas-Quarneti, N., \& Magalhães, L. (2018). Body-map storytelling as a health research methodology: Blurred lines creating clear pictures. Forum: Qualitative Social Research, 19, 2. https://doi.org/10.17169/fqs-19.2.2858.

Geertz, C. (1973). The interpretation of cultures: Selected essays. New York: Basic Books.

Glaser, B., \& Strauss, A. (1967). The discovery of grounded theory. Chicago: Aldine.

Hammond, C. (2005). The wider benefits of adult learning: An illustration of the advantages of multi-method research. International Journal of Social Research Methodology, 8, 239-255. https://doi. org/10.1080/13645570500155037.

Harder, A. T., Knorth, E. J., \& Kalverboer, M. E. (2013). A secure base? The adolescent-staff relationship in secure residential youth care. Child and Family Social Work, 18, 305-317. https://doi.org/ 10.1111/j.1365-2206.2012.00846.x.

Harms, L. (2010). Understanding human development: A multidimensional approach (2nd ed.). South Melbourne: Oxford University Press.

Hartling, L. (2009). Strengthening resilience in a risky world: It's all about relationships. In J. Jordan (Ed.), The power of connection: Recent developments in relational-cultural theory (pp. 87-117). London: Routledge.

Hopwood, T., Schutte, N., \& Loi, N. (2019). Stress responses to secondary trauma: Compassion fatigue and anticipatory traumatic reaction among youth workers. Social Science Journal, 56, 337348. https://doi.org/10.1016/j.soscij.2018.08.008.

Jakobsen, I. S., \& Christiansen, E. (2011). Young people's risk of suicide attempts in relation to parental death: A population-based register study. Journal of Child Psychology and Psychiatry, 52, 176-183. https://doi.org/10.1111/j.1469-7610.2010.02298.x.

Jordan, J. (2014). Relational-cultural theory. In D. Coghlan \& M. Brydon-Miller (Eds.), The SAGE encyclopedia of action research (pp. 681-683). London: SAGE.

Kirkpatrick, S., Barlow, J., Stewart-Brown, S., \& Davis, H. (2007). Working in partnership: User perceptions of intensive home visiting. Child Abuse Review, 16, 32-46. https://doi.org/10.1002/ car.972.

Lamb, K., Humphreys, C., \& Hegarty, K. (2018). "Your behaviour has consequences": Children and young people's perspectives on reparation with their fathers after domestic violence. Children and Youth Services Review, 88, 164-169. https://doi.org/10.1016/j. childyouth.2018.03.013.

Lincoln, Y., \& Guba, E. (1985). Naturalistic inquiry. London: SAGE. Lingler, J. H., Schmidt, K. L., Gentry, A. L., Hu, L., \& Terhorst, L. A. (2014). A new measure of research participant burden: Brief 
report. Journal of Empirical Research on Human Research Ethics, 9, 46-49. https://doi.org/10.1177/1556264614545037.

Mah, K., Gladstone, B., King, G., Reed, N., \& Hartman, L. R. (2019). Researching experiences of childhood brain injury: Co-constructing knowledge with children through arts-based research methods. Disability and Rehabilitation. https://doi.org/10.1080/09638 288.2019.1574916.

Malvaso, C., Delfabbro, P., Hackett, L., \& Mills, H. (2016). Service approaches to young people with complex needs leaving outof-home care. Child Care in Practice, 22, 128-147. https://doi. org/10.1080/13575279.2015.1118016.

Mason, C. (2012). Social work the 'art of relationship': Parents' perspectives on an intensive family support project. Child and Family Social Work, 17, 368-377.

McCloughen, A., Foster, K., Marabong, N., Miu, D., \& Fethney, J. (2015). Physical health risk behaviours in young people with mental illness. Issues in Mental Health Nursing, 36, 781-790. https:// doi.org/10.3109/01612840.2015.1036480.

Mott, R., Keller, K., Britt-Rankin, J., \& Ball, A. (2018). 'Out of place around other people': Experiences of young people who live with food insecurity. Children and Society, 32, 207-218. https://doi. org/10.1111/chso. 12270 .

Munford, R., \& Sanders, J. (2017). Harnessing resistance in interventions with young people. Journal of Social Work Practice, 31, 79-93.

O'Leary, P., Tsui, M. S., \& Ruch, G. (2013). The boundaries of the social work relationship revisited: Towards a connected, inclusive and dynamic conceptualisation. British Journal of Social Work, $43,135-153$

Oliver, C., \& Charles, G. (2016). Enacting firm, fair and friendly practice: A model for strengths-based child protection relationships? British Journal of Social Work, 46, 1009-1026.

Orchard, T. (2017). Remembering the body: Ethical issues in body mapping research. London: Springer.

Paget, A., Parker, C., Heron, J., Logan, S., Henley, W., Emond, A., \& Ford, T. (2018). Which children and young people are excluded from school? Findings from a large British birth cohort study, the Avon Longitudinal Study of Parents and Children (ALSPAC). Child: Care, Health and Development, 44, 285-296. https://doi. org/10.1111/cch.12525.

Parr, S. (2016). Conceptualising 'the relationship' in intensive key worker support as a therapeutic medium. Journal of Social Work Practice, 30, 25-42.

Reimer, C. E. (2014). Using friendship to build professional family work relationships where child neglect is an issue: Worker perceptions. Australian Social Work, 67, 315-331. https://doi. org/10.1080/0312407X.2013.815240

Sandu, R. D. (2019). What aspects of the successful relationships with professional helpers enhance the lives of young people facing significant disadvantage? Children and Youth Services Review. https ://doi.org/10.1016/j.childyouth.2019.104462.

Shevellar, L., \& Barringham, N. (2016). Working in complexity: Ethics and boundaries in community work and mental health. Australian Social Work, 69, 181-193.

Silveira, F. S., \& Boyer, W. (2015). Vicarious resilience in counselors of child and youth victims of interpersonal trauma. Qualitative Health Research, 25, 513-526. https://doi.org/10.1177/10497 32314552284
Smith, L., \& Dowse, L. (2019). Times during transition for young people with complex support needs: Entangled critical moments, static liminal periods and contingent meaning making times. Journal of Youth Studies, 22, 1327-1344. https://doi. org/10.1080/13676261.2019.1575346.

Smyth, P. (2017). Working with high-risk youth: A relationship-based practice framework. London: Routledge.

Stafford, L., Marston, G., Chamorro-Koc, M., Beatson, A., \& Drennan, J. (2017). Why one size fits all approach to transition in disability employment services hinders employability of young people with physical and neurological disabilities in Australia. Journal of Industrial Relations, 59, 631-651. https://doi.org/10.1177/00221 85617723379.

Storø, J. (2017). Which transition concept is useful for describing the process of young people leaving state care? A reflection on research and language. European Journal of Social Work, 20, 770-781. https://doi.org/10.1080/13691457.2016.1255879.

Strnadova, I., \& Cumming, T. (2016). Lifespan transitions and disability: A holistic perspective. London: Routledge.

Sulimani-Aidan, Y. (2017). Future expectations as a source of resilience among young people leaving care. British Journal of Social Work, 47, 1111-1127. https://doi.org/10.1093/bjsw/bcw077.

te Riele, K. (2004). Youth transition in Australia: Challenging assumptions of linearity and choice. Journal of Youth Studies, 7, 243-257.

Turney, D. (2012). A relationship-based approach to engaging involuntary clients: The contribution of recognition theory. Child and Family Social Work, 17, 149-159.

Ungar, M., Liebenberg, L., \& Ikeda, J. (2014). Young people with complex needs: Designing coordinated interventions to promote resilience across child welfare, juvenile corrections, mental health and education services. British Journal of Social Work, 44, 675-693. https://doi.org/10.1093/bjsw/bcs147.

Ungar, M., Liebenberg, L., Landry, N., \& Ikeda, J. (2012). Caregivers, young people with complex needs, and multiple service providers: A study of triangulated relationships. Family Process, 51, 193-206.

van Bijleveld, G. G., Dedding, C. W. M., \& Bunders-Aelen, J. F. G. (2014). Seeing eye to eye or not? Young people's and child protection workers' perspectives on children's participation within the Dutch child protection and welfare services. Children and Youth Services Review, 47, 253-259. https://doi.org/10.1016/j. childyouth.2014.09.018.

Vander Laenen, F. (2009). "I don't trust you, you are going to tell": Adolescents with emotional and behavioural disorders participating in qualitative research. Child: Care, Health and Development, 35, 323-329. https://doi.org/10.1111/j.1365-2214.2009.00936.x.

Wilson, C., \& Flicker, S. (2014). Arts-based action research. In D. Coghlan \& M. Brydon-Miller (Eds.), The SAGE encyclopedia of action research (pp. 59-62). London: SAGE.

Publisher's Note Springer Nature remains neutral with regard to jurisdictional claims in published maps and institutional affiliations. 